\title{
COMO OLHAR E PENSAR O CORPO JOVEM
}

\author{
José Geraldo Soares Damico*
}

RESUMO: $\mathrm{O}$ artigo é parte de uma dissertação de mestrado que discutiu alguns dos modos pelos quais jovens mulheres significam e vivenciam, contemporaneamente, o cuidado com o corpo. Inscreve-se nos campos dos estudos de gênero, nas vertentes que têm proposto aproximações críticas com a perspectiva pós-estruturalista de Michel Foucault. Utiliza a abordagem metodológica da análise de discurso para examinar discussões travadas por 18 jovens de 13 a 15 anos, alunas de uma escola pública no Rio Grande do Sul, que integraram grupos focais cujas reuniōes se desenvolveram durante dois meses, em 2004. Utilizo a metáfora do caleidoscópio para multiplicar o olhar sobre o corpo.

Palavras-chave: Corpo. Gênero. Juventude. Caleidoscópio.

How TO LOOK AT AND THINK THE YOUNG BODY

ABSTRACT: This article is part of a dissertation that discussed some of the ways in which young women give meaning to, learn and experience the body care in contemporary society. It is inscribed in the fields of gender studies, and particularly within the critical strands aligned with Michel Foucault's poststructuralist perspective. It uses the methodological approach of discourse analysis to examine discussions with 18 girls between the ages of 13 and 15 , students from a public school in the state of Rio

Doutora em Educação e professora do Curso de Educação Física e do Mestrado em Educação nas Ciências da Universidade Regional do Noroeste do Estado do Rio Grande do Sul (Unijuí).E-mail: simone@unijui.edu.br 
Grande do Sul, who joined focal group meetings developed during two months in 2004. I use the kaleidoscope metaphor to multiply the views on the body.

Key words: Body. Gender. Youth. Kaleidoscope.

\section{Introdução}

$\sqrt{2}$

ste artigo é parte de uma dissertação ${ }^{1}$ em que discuti alguns dos modos pelos quais jovens mulheres significam, apre(e)ndem e vivenciam, contemporaneamente, o cuidado com o corpo. Tomando como referência os estudos de gênero e os estudos culturais, especificamente aquelas vertentes que têm proposto uma aproximação crítica com a perspectiva pós-estruturalista de Michel Foucault, examinei textos que resultaram de discussóes realizadas com 18 jovens, entre 13 e 15 anos, alunas da oitava série do ensino fundamental e do primeiro ano do ensino médio do Colégio de Aplicação da Universidade Federal do Rio Grande do Sul (CAP/UFRGS). Essas discussões foram conduzidas em seis reuniōes de dois grupos focais, realizadas em 2004, as quais foram gravadas e, posteriormente, transcritas para análise. As falas das jovens foram exploradas tomando como base os conceitos de cultura, discurso, gênero e poder, com o propósito de problematizar os diferentes modos pelos quais o cuidado com o corpo é significado, apre(e)ndido e vivido nesse contexto.

As mulheres jovens têm sido posicionadas como personagens centrais do culto ao corpo. Tal posição se caracteriza por argumentos que descrevem as jovens (e a relação que estas estabelecem com seus corpos) como belas e sedutoras e, ao mesmo tempo, irresponsáveis, emocionalmente problemáticas e personagens principais de condutas e situações de risco, tais como gravidez precoce, doenças sexualmente transmissíveis, uso de drogas, desordens alimentares e sedentarismo.

Esse estatuto de ameaça a si mesmas e aos outros, atribuído às mulheres jovens, evidenciado por muitos discursos médicos, psicológicos e educacionais, parece fazer eco aos discursos que colocam a adolescência como uma etapa da vida, vivida do mesmo modo por todos os jovens, que seria naturalmente conturbada e que se caracterizaria pela contestação em relação às demandas das gerações mais velhas, entre outras coisas. 
Nesse contexto, os processos atuais de construção dos corpos femininos jovens, através das práticas corporais ou das imagens culturais em que tais práticas se apoiam, constituem-se em preocupações centrais de muitas garotas.

No caso do corpo feminino jovem, este tem sido objeto de padronização, tanto em termos de tamanho (altura e largura) quanto em termos de forma (esbelteza, rigidez muscular e curvas) e, "nesta construção, o que está em jogo são as energias e os recursos do corpo feminino, uma verdadeira batalha política” (Adelman, 1999, p. 451).

Em tais discursos, as noções de saúde, bem-estar e alimentação são constantemente renovadas e rearticuladas, instituindo formas de cuidado com significações distintas de prazer, contenção, resistência, feminilidade ou masculinidade. Nesse caso, determinadas práticas corporais passam a ser objeto de uma atenção constante, na qual o cuidado com uma alimentação tida como equilibrada, por exemplo, resultaria em uma aparência mais saudável, e exercícios físicos orientados seriam determinantes para uma saúde perfeita. Em suma, essas práticas vão compondo um estilo de vida ativo, ${ }^{2}$ em que a autovigilância e a motivação são a ordem do dia.

A busca pela magreza, no caso das mulheres jovens, está dimensionada por processos culturais que constituem práticas corporais objetivadas em uma série de cuidados com o corpo. Em sua relação com corpos generificados, as garotas (mais do que os garotos) são educadas para exibir seu corpo de acordo com a moda, usando miniblusas, calças e minissaias de cintura baixa, biquínis fio dental, blusas de alcinhas, chinelos e tamancos de plataforma. Esses artifícios podem funcionar como pequenos constrangimentos, quando o corpo não está adequadamente preparado para exibir, por exemplo, uma barriga em forma ou um bumbum arrebitado: "o modelo de beleza que deve ser alcançado resulta de um esforço, de um autocontrole do corpo, de uma educação cuidadosa, de uma certa predisposição para a tortura, de uma retomada bíblica” (Soares, 2003, p. 16).

Unidades ópticas ou da organização das análises

A dieta e o fitness seriam dois exemplos do processo de olhar e pensar o corpo. Nos casos das jovens que tomam laxante durante o dia para aparecer magras nas festas noturnas ou que comem uma barra de 
chocolate às escondidas, esses comportamentos parecem significar, para elas, uma transgressão calculada.

No período do trabalho de campo - num contexto em que circulavam diferentes forças e em que significados iam sendo construídos e negociações e práticas sociais iam sendo enunciadas -, busquei estabelecer uma leitura que produzisse um movimento analítico que transitasse por diferentes lugares, como o lugar-escola e o lugar-corpo, e por diferentes processos: a correta gestão do corpo e o prazer de ser olhada e desejada; a resistência para não se submeter às normas; a preguiça culpabilizada e a celebração da força de vontade; as dietas em momentos específicos e os vômitos e desmaios experimentados nas semanas de festas consideradas importantes. Conforme Skliar (2003, p. 67-68),

Existe um olhar que parte da mesmidade. Outro que se inicia no outro, na expressividade de seu rosto. Talvez esta distinção seja uma forma para poder olhar entre aquelas representações, aquelas imagens que tomam como ponto de partida e como ponto de chegada o eu mesmo, o mesmo - o sumidouro, o refúgio do próprio corpo e do mesmo olhar -, e aquelas que começam no outro e se submetem a seu mistério, seu distanciamento, sua rebeldia, sua expressividade, sua irredutibilidade.

Mesmidade e alteridade, pontos de vista para diferentes olhares que me permitiram experimentar que o como se vê e o que se vê são determinados pelas relações de poder que carregam em si também a possibilidade de subversão. A análise das diferentes falas que as jovens produziram no lugar-escola possibilita delinear discursos e estratégias conflitantes e, desse modo, não se pode dizer que os discursos da boa forma sejam uniformemente coercitivos. O que estaria na base desse processo é a compreensão do eu como um processo reflexivo, num olhar constante sobre si mesmo.

A análise propriamente dita deu-se numa articulação entre os elementos que compóem os enunciados de uma discursividade sobre os corpos femininos jovens e a organização desses elementos em relação ao cuidado que as jovens estabelecem consigo mesmas. Tenho claro que o que me propus a fazer - e espero ter conseguido - foi organizar os enunciados de uma determinada forma e não de muitas outras possíveis, agrupando as unidades temáticas de acordo com três definições diferentes de um objeto óptico, o caleidoscópio. 
O caleidoscópio ${ }^{3}$ é um objeto para o olhar, que usa as características dos prismas para criar imagens coloridas e diferentes que se movem. Dependendo do ângulo em que os espelhos são colocados, irão se formar imagens diferentes. A palavra vem do grego, em que kalos quer dizer beleza, eidos significa forma e skopien é olhar, ou seja, é o objeto óptico que nos faz ver belas formas. Santos (1998, p. 19), ao discutir o uso da metáfora do caleidoscópio, afirma:

(...) a metáfora cumpre também a função de explicar um mundo em constante mudança, porque cada imagem formada não é igual a outra. Embora mude a forma, multiplique a cena ou o objeto observado, o caleidoscópio não os transforma em outra coisa, a alteração retém o que foi alterado; em um exemplo: o corpo continua corpo, mas o olhar sobre ele se modifica.

As unidades que organizei se formam em torno das questões sobre o cuidado que se articulam ao objeto óptico, ao priorizar as multiplicidades, a produção de fluxos e os jogos de linguagem.

As duas unidades temáticas estão organizadas de modo a formar um corpo discursivo que possa responder às questóes de pesquisa, em que a ideia central é a multiplicação dos discursos sociais, da posição de sujeito das falantes e, por último, das continuidades das coisas ditas e das variedades das modalidades enunciativas (Fischer, 1996). Assim, ao operar metodologicamente com a análise de discurso de inspiração foucaultiana, busquei trabalhar as falas, decompô-las, multiplicar os sentidos que elas podem conter, bem como localizar os rastros ou as marcas dos discursos que se articulam para torná-las possíveis.

\section{As críticas instituindo um jeito de ser jovem}

Um dos desdobramentos da discussão que fizemos acerca do tema das críticas foi a forma como as jovens participantes da pesquisa lidam com os apelidos ${ }^{4}$ e as brincadeiras que os colegas fazem sobre alguma característica física, como aparece nas transcrições que seguem.

Clara - "E isso daí é horrível, porque, se uma pessoa te chama de um jeito, daí todo mundo vai te chamar daquele jeito".

Flávia - “Às vezes, tu não estás nem aí porque tu não és muito magra nem muito gorda, mas, a partir do momento em que todo mundo começa a se 
arriar, te criticar e rir da tua cara, daí tu te sentes mal e tu queres mudar o teu corpo".

Kátia - "E principalmente assim com as pessoas com quem tu convives todos os dias, sabe? Daí, se tu não mudares, se tu continuares assim, ainda mais que tu já estás meio insegura. $\mathrm{Na}$ adolescência, todo mundo já é meio insegura, então, se os outros se arriam, ainda vai piorar a situação. Tu vais te sentir: 'ai, e agora, eu sou uma idiota, eu sou feia'”'.

Cabe ressaltar que o termo crítica denota discernimento, eleição e decisão, e o termo julgamento remete a uma lógica jurídica do dever e da norma. Em ambos os casos, os indivíduos utilizam certos critérios para interpretar, apreciar ou avaliar uma dada situação (Larrosa, 1995). Nos fragmentos apresentados, as críticas ou os julgamentos que levam as jovens a se colocarem como alvo dos olhares do grupo são constituídos a partir de critérios pessoais e, concomitantemente, de certa racionalidade, ao utilizarem-se atributos mais ou menos padronizados (peso, forma de partes do corpo), como se todas/os as/os que estivessem perto delas e, inclusive, elas próprias pudessem ocupar o lugar de quem expressa o olhar, ao mesmo tempo em que não são observadas diretamente. Outra consequência é a possibilidade de um efeito contagiante, como se o apelido ou a crítica funcionassem como uma caricatura que ressaltasse algo que ninguém percebe num primeiro momento e que depois se torna um sinal identitário, lembrado por todos.

Para Flávia, mesmo as meninas que não são as mais visadas, como ela, por não serem nem muito gordas, nem muito magras, seriam alvos de brincadeiras isoladas. O problema maior é quando algum detalhe anatômico (pernas muito finas, seios muito pequenos) passa a ser ressaltado negativamente pelo grupo e se torna motivo para brincadeiras constantes. Provavelmente, mesmo a garota que não se percebia com alguma imperfeição passaria a buscar modificar seu corpo.

As palavras arriar, criticar e rir, apesar de serem ditas em sequência pela jovem, não são sinônimos. Arriar, no linguajar do cotidiano jovem, significa deitar-se, ou seja, causar abatimento, abater, ao passo que rir denota zombaria. Não se trata aqui de posicionar as moças como vítimas ou algozes, mas de demonstrar como as relações de poder entre jovens podem manter ou produzir diferentes hierarquias em relação às normas de relaçooes consigo próprias e demonstrar, ainda, que muitas vezes as críticas podem ser cruéis e até mesmo violentas. 
O modo como tais críticas são recebidas como verdades em si parece receber sentido naquilo que é explicitado como uma característica naturalizada na adolescência, um período da vida que seria marcado por insegurança, dúvidas e rebeldia. Essa naturalização de uma dada adolescência problemática é possível numa ordem discursiva que se apoia nos enunciados formulados em distintos campos de saber, que se articulam para afirmar, através da psicologia, da pedagogia ou da medicina, que esse período da vida traz inseguranças e sofrimentos, dadas as mudanças orgânicas ou a transição emocional que a passagem entre a infância e a vida adulta produz. No entanto, mesmo entre os adultos, que dificilmente permitem tal nível de criticismo, pelo menos abertamente, situações como as descritas anteriormente causariam tristeza, frustração e constrangimento.

Nas relações que se estabelecem com o mundo, uma das principais preocupaçôes das jovens participantes está relacionada à opinião das pessoas a seu respeito. Nesse sentido, o espaço de convivência no lugarescola parece privilegiado, na medida em que nele convivem diariamente por muitas horas. Ser aceita ou não, sofrer ou não com as observações e as críticas, buscar modificar-se para estar mais adequada, a fim de destacar-se ou se tornar mais invisível, são estratégias e efeitos constitutivos desses processos de crítica. A seguir, apresento uma das falas que escolhi entre várias outras, em que a jovem diz:

Janaína - "Eu acho que é uma característica de adolescente e tu vais aprendendo a lidar com isso. Até porque tem toda aquela coisa de 'preciso que me achem bonita"'.

Para Janaína, ainda falando da mesma temática, mas em outro encontro grupal, os incômodos que causam as observaçôes dos outros servem como uma via de aprendizado, que vai da adolescência ao tornar-se mulher. A jovem destaca o reconhecimento da sua beleza como uma necessidade inerente à adolescência. Aqui, este período tem atributos que lhe seriam intrínsecos, como a necessidade de reconhecimento e como uma fase de aprendizagem e de amadurecimento. As jovens parecem aprender que as experiências consigo mesmas podem ser reguladas pelas críticas, desde recusar o seu corpo como ele é ou até mesmo buscar modos de modificá-lo. 
As transformações na experiência com o corpo feminino, provocadas por uma série de regulações, como as críticas dos colegas ou as propostas pelas tecnologias biomédicas e até pelos livros de autoajuda, "propõem aos indivíduos que há mecanismos tecnológicos para se regrar a forma do corpo, reduzir a distância entre o que quer o pensamento e o que quer o corpo" (Vaz, 1999, p. 105).

\section{O olhar dirigido ao outro}

Ao perguntar como suas amigas faziam quando queriam emagrecer, uma das jovens respondeu assim:

Araci - "A Beatriz tem bastante preocupação com a comida. Assim, eu acho que ela tenta se controlar, às vezes, deixando de comer certas coisas. Às vezes, não é necessário, porque ela não é gorda. Ela só acha que, às vezes, está gorda. Mas, por exemplo, têm aquelas garotas que vomitam e que param de comer porque acham que são gordas. Por mais que olhem e sejam realmente magras, magras, magras mesmo, elas sempre se veem gordas e sempre veem que têm que tentar mais, têm que vomitar mais, têm que deixar de comer".

Araci, ao comentar as preocupaçóes e os cuidados com o peso demonstrado por uma colega (também participante da pesquisa), ressalta que esta não precisaria realizar restriçôes na sua alimentação, já que, em sua opinião, ela não é gorda; ela só se acha, às vezes, gorda. É possível que a jovem esteja falando entre o ser e o estar gorda a partir de exame minucioso que as jovens realizam sobre si mesmas em certas condições (antes de festas, em função de determinadas roupas), reparando nas saliências, vendo-se refletidas no espelho ou comparando-se com outras mulheres que aparecem nas revistas ou na mídia em geral.

O desejo das mulheres, mesmo as mais jovens, de transformar o corpo conforme padrões aceitáveis, segundo as normas sociais, e de adquirir uma imagem que inspire empoderamento e outras formas de prazer (como o sexual e o erótico) pode resultar na necessidade de recortar algo de si mesmas, provavelmente encorajando algum grau de controle sobre o prazer que a comida poderia oferecer. Assim, percebe-se que Araci fala de meninas que vomitam, mesmo que sejam magras, para ficarem mais magras ainda. A estratégia de tentar controlar o peso através do ato 
de vomitar aparece como uma das mais utilizadas pelas jovens participantes da pesquisa. Posso destacar aqui que, entre as mulheres jovens, vomitar pode ser caracterizado como uma prática de um ascetismo contemporâneo. Ortega (2002, p. 145), apoiado em Foucault, comenta que a ascese "é o conjunto ordenado de exercícios disponíveis, recomendados e até obrigatórios, utilizáveis pelos indivíduos num sistema moral, filosófico e religioso para atingir um objetivo específico".

O corpo é consumido como imagem bela a ser mostrada e vendida, já que o consumo se configura como uma atividade de conquista do prazer, e não como necessidade - muitas vezes não se consomem mercadorias porque se está com fome ou por precisar vestir-se, por exemplo.

\section{Para finalizar...}

As condiçōes de existência de um discurso que institui e, ao mesmo tempo, constitui o sujeito jovem ocorrem na medida em que a compreensão das relações de poder-saber permite que se mostre a positividade e a materialidade dos discursos. Essa materialidade pode aparecer quando se fazem ao corpus discursivo questôes como estas: Quem pode falar o quê? Para quem e em que lugar? De acordo com Foucault (1999, p. 59),

É sempre no âmbito da materialidade que ele [o discurso] se efetiva, que é efeito; ele possui seu lugar e consiste na relação, coexistência, dispersão, recorte, acumulação, seleção de elementos materiais; não é o ato nem a propriedade de um corpo; produz-se como efeito de e em uma dispersão material.

Considerando a centralidade do corpo feminino jovem na cultura contemporânea - sujeito social de uma série de discursos, na medida em que diferentes instâncias procuram produzir e reproduzir um gestual, um vocabulário e práticas cotidianas jovens, nas quais práticas corporais que envolvem modos de alimentar-se, fazer exercícios e vestir-se figuram como elementos básicos -, interrogo os discursos que delimitaram as discussões com as jovens. Dessa forma, busco mapear como poderes e saberes produzem sentidos e como as jovens estudantes investigadas estabelecem as relações consigo diante de um conjunto de normas, regras e cuidados necessários para um aperfeiçoamento de seu modo de vida. 
Portanto, quando analiso os enunciados nos discursos que tornam possíveis as falas das jovens, interessa-me ressaltar essas formações discursivas para verificar de que maneira as participantes se referem ao seu corpo, como e com que frequência utilizam tal enunciado, como empregam um determinado conceito e, finalmente, para qual estratégia o enunciado está sendo empregado, caracterizando a formação discursiva pela regularidade com que determinadas práticas se apresentam e se materializam. Foi nesse sentido que busquei perceber o efeito das falas. O que está em questão é o descentramento do sujeito, deslocando-o do lugar central e privilegiado, compreendendo como, em diferentes épocas, as pessoas são transformadas e colocadas em determinadas posições de sujeitos.

\section{Notas}

1. Dissertação de mestrado de José G. S. Damico, intitulada Quantas calorias eu preciso Igastar] para emagrecer com saúde? Como mulheres jovens aprendem estratégias para cuidar do corpo. Foi orientada por Dagmar Estermann Meyer e coorientada por Dora L. de Oliveira, no Programa de Pós-Graduação em Educação da Universidade Federal do Rio Grande do Sul - linha de pesquisa "Educação, sexualidade e relações de gênero". Defesa pública realizada em janeiro de 2005.

2. O estilo de vida ativo, ou a mudança no estilo de vida que resulte em uma vida ativa é um dos principais elementos do documento final da Conferência Internacional de Promoção da Saúde, realizada em Ottawa (Canadá), em 1986. A importância deste documento reside em que nele se lançaram as diretrizes para as principais transformaçôes na saúde pública, em sentido amplo, na maioria dos países (Palma et al., 2003).

3. O caleidoscópio é um artefato ótico que consiste num pequeno tubo cilíndrico, no fundo do qual há pequenos pedaços coloridos de vidro ou de outro material, cuja imagem é refletida por espelhos dispostos ao longo do tubo, de modo que, quando se movimenta o tubo ou esses pedaços, formam-se imagens coloridas e múltiplas. A dissertação de Luis Henrique Sacchi dos Santos, Um olhar caleidoscópico sobre as representaçôes culturais de corpo (1998), utiliza a metáfora do caleidoscópio desde o título. Outros autores como Barthes (1982) e Deleuze (1991) têm feito uso da mesma metáfora.

4. Mesmo reconhecendo a ampla repercussão do termo bullying nos dias de hoje, para explicar e denunciar as relações de desigualdade entre alunos/as, preferi não adotá-lo ao longo do texto, por entender que este termo também faz parte de um amplo processo de patologização e criminalização dos comportamentos e condutas de escolares.

\section{Referências}

ADELMAN, M. Mulheres atletas: ressignificaçôes da corporalidade feminina? Revista dos Estudos Feministas, Florianópolis, v. 11, n. 2, p. 445-465, jul.-dez. 1999. 
BARTHES, R. O jogo do Caleidoscópio. In: BARTHES, R. O grão da voz. Lisboa: 1982.

DELEUZE, G. Foucault. São Paulo: Brasiliense, 1991.

FISCHER, R.M.B. Adolescência em discurso: mídia e produção de subjetividade. 1996. Tese (Doutorado em Educação) - Faculdade de Educação da Universidade Federal do Rio Grande do Sul, Porto Alegre.

FOUCAUlT, M. A ordem do discurso. São Paulo: Loyola, 1999.

LARROSA, J. Tecnologias do eu e educação. In: SILVA, T.T. (Org.). O sujeito da educação. Petrópolis: Vozes, 1995.

NAHAS, M. Atividade física, saúde e qualidade de vida: conceito e sugestôes para um estilo de vida ativo. Londrina: Midiograf, 2003.

ORTEGA, F. Da ascese à bio-ascese ou do corpo submetido à submissão do corpo. In: RAGO, M.; ORLANDI, L.; VEIGA-NETO, A. (Org.) Imagens de Foucault e Deleuze: ressonâncias nietzchianas. Rio de Janeiro: DP\&A, 2002.

PALMA, A.; ESTEVÃO, A.; BAGRICHEVSKY, M. Análise sobre os limites da interferência causal no contexto investigativo sobre o exercício físico e saúde. In: PALMA, A.; ESTEVÃO, A.; BAGRICHEVSKY, M. (Org.). Saúde em debate na educação física. Blumenau: Edibes, 2003.

SANTOS, L.H.S.S. Um olhar caleidoscópico sobre as representaçôes culturais de corpo. 1998. Dissertação (mestrado em Educação) - Faculdade de Educação da Universidade Federal do Rio Grande do Sul, Porto Alegre.

SOARES, C. Visibilidade do corpo (apresentação). Pro-Posiçôes, Campinas, v. 14, n. 2, p. 15-19, maio/ago. 2003.

VAZ, P.R.G. Corpo e risco. Fórum Média, Viseu, v. 1, n. 1, p. 101-111, 1999.

Recebido em 5 de abril de 2011.

Aprovado em 30 de junho de 2012. 